\title{
Density of the continental roots: compositional and thermal contributions
}

\author{
Mikhail K. Kaban ${ }^{\mathrm{a}, *}$, Peter Schwintzer ${ }^{\mathrm{a}}$, Irina M. Artemieva ${ }^{\mathrm{b}}$, \\ Walter D. Mooney ${ }^{\mathrm{c}}$ \\ a GeoForschungsZentrum Potsdam (GFZ), Dept. 1, Telegrafenberg, A 17, 14473 Potsdam, Germany \\ b EOST, Institut de Physique du Globe, Université Louis Pasteur, 5 rue Rene Descartes, 67084 Strasbourg, France \\ c U.S. Geological Survey, MS 977, 345 Middlefield Road, Menlo Park, CA 94025, USA
}

Received 29 October 2002; received in revised form 20 January 2003; accepted 28 January 2003

\begin{abstract}
The origin and evolution of cratonic roots has been debated for many years. Precambrian cratons are underlain by cold lithospheric roots that are chemically depleted. Thermal and petrologic data indicate that Archean roots are colder and more chemically depleted than Proterozoic roots. This observation has led to the hypothesis that the degree of depletion in a lithospheric root depends mostly on its age. Here we test this hypothesis using gravity, thermal, petrologic, and seismic data to quantify differences in the density of cratonic roots globally. In the first step in our analysis we use a global crustal model to remove the crustal contribution to the observed gravity. The result is the mantle gravity anomaly field, which varies over cratonic areas from -100 to $+100 \mathrm{mGal}$. Positive mantle gravity anomalies are observed for cratons in the northern hemisphere: the Baltic shield, East European Platform, and the Siberian Platform. Negative anomalies are observed over cratons in the southern hemisphere: Western Australia, South America, the Indian shield, and Southern Africa. This indicates that there are significant differences in the density of cratonic roots, even for those of similar age. Root density depends on temperature and chemical depletion. In order to separate these effects we apply a lithospheric temperature correction using thermal estimates from a combination of geothermal modeling and global seismic tomography models. Gravity anomalies induced by temperature variations in the uppermost mantle range from -200 to $+300 \mathrm{mGal}$, with the strongest negative anomalies associated with mid-ocean ridges and the strongest positive anomalies associated with cratons. After correcting for thermal effects, we obtain a map of density variations due to lithospheric compositional variations. These maps indicate that the average density decrease due to the chemical depletion within cratonic roots varies from $1.1 \%$ to $1.5 \%$, assuming the chemical boundary layer has the same thickness as the thermal boundary layer. The maximal values of the density drop are in the range 1.7-2.5\%, and correspond to the Archean portion of each craton. Temperatures within cratonic roots vary strongly, and our analysis indicates that density variations in the roots due to temperature are larger than the variations due to chemical differences.
\end{abstract}

(C) 2003 Elsevier Science B.V. All rights reserved.

* Corresponding author. Tel.: +49-331-288-1172; Fax: +49-331-288-1169.

E-mail addresses: kaban@gfz-potsdam.de (M.K. Kaban), psch@gfz-potsdam.de (P. Schwintzer), irina@eost.u-strasb.fr (I.M. Artemieva), mooney@usgs.gov (W.D. Mooney). 
Keywords: gravity; heat flow; density; lithosphere; craton

\section{Introduction}

The lithospheric roots beneath the Precambrian cratons are colder than younger continental or oceanic lithosphere [1-3]. Despite these low temperatures, cratons do not show positive anomalies in the observed gravity field or geoid $[4,5]$. To explain this contradiction, Jordan [4] postulated the isopycnic (equal-density) hypothesis for which the density increase caused by low temperatures is compensated by a density decrease due to a compositional difference (i.e. chemical depletion, mainly in $\mathrm{Fe}$ and $\mathrm{Al}$ ) of the roots with respect to the surrounding mantle. Experimental studies of the density of cratonic peridotites and theoretical density constraints for different chemical compositions of the upper mantle generally support this hypothesis and show that the cratonic lithosphere is less dense than non-cratonic uppermost mantle under the same conditions by up to $1.5-2.5 \%$ [6-10].

The validity of the isopycnic hypothesis is still debated. It is not clear if a downward density increase due to compositional changes (i.e. decreasing depletion with depth) exactly compensates a temperature increase with depth. Recent petrologic studies of peridotites from the Kaapvaal craton indicate that the change of bulk peridotite density with depth does not follow the isopycnic curve of Jordan [11]. Shallow peridotites from the Kaapvaal craton are less dense, while deep $(>120 \mathrm{~km})$ high-temperature peridotites are denser than predicted by the isopycnic hypothesis [12]. Similarly, the studies of peridotite xenoliths from the Slave and the Tanzanian cratons show that the density increase with depth is much steeper than predicted by isopycnic curves $[13,14]$.

Furthermore, petrological results for the Siberian craton [16] indicate a peak in lithospheric depletion at a depth of about $130 \mathrm{~km}$, which is in agreement with the results of Forte and Perry [15], who have inverted a large set of geodynamic data related to mantle convection to come to the same conclusion.
Thus, the petrological studies do not give a conclusive answer to the question of the density of continental roots. The problem is that they provide data for restricted local areas, usually in the vicinity of kimberlite pipes. At the same time, these data show that the lithosphere is heterogeneous even over small distances. For example, Gaul et al. [50] found significant differences of the forsterite content versus depth between two locations in the Daldyn-Alakit field in Siberia and between two locations in southeastern Australia. The use of such individual, sparse probes for an estimation of the average density of continental roots, which is important to know for modeling their dynamics, may give biased results. In this study the emphasis is on the density properties generalized over very large volumes of the continental lithosphere.

The positive gravity effect (i.e. density increase) due to low temperatures in the cratonic upper mantle could be at least partially compensated by an increase in crustal thickness. A global analysis of the seismic data indicates that the position of the Moho under Precambrian cratons is, on average, somewhat deeper than under Phanerozoic continental areas [17]. Thus, a compositional change in the lithospheric root is not the only factor providing a close to zero gravitational signal over cratons.

Besides identifying the common characteristics of continental roots, it is important to investigate the sources for systematic differences in their properties between cratons. Seismic tomography studies and thermal modeling show substantial variations in the temperature distribution and seismic velocities of cratonic lithosphere. Seismic tomography reveals differences in the thickness of the cratonic lithosphere $(150-350 \mathrm{~km})$ [18-20]. Thermal modeling of heat flow data confirms such thickness variations [3]. In this paper two typical values of the thickness of Archean/Proterozoic roots are found: $300-350 \mathrm{~km}$ and $200-220$ $\mathrm{km}$. The authors argue that the thickness variations may be compensated by differences in the crustal structure, while the density decrease due 
to depletion is about the same (up to $1.5 \%$ ). On the other hand, some variations in lithospheric mantle composition and, thus, in the mantle density, are found in petrologic studies of the mantlederived peridotite xenoliths in different cratons [10,21-23] and in global geodynamic modeling [15].

The goal of this study is to combine gravity, thermal, and seismic data to check the validity of the isopycnic hypothesis [11] and to examine how composition and density vary within continental roots. Unlike previous studies, our analysis is based on the interpretation of the mantle gravity anomalies. These anomalies are calculated by subtracting the gravitational effect of the crust (including topography) from the observed gravity field. We also calculate the residual topography, which is understood here as that topography not compensated by the crust.

An interpretation of the observed global gravity field and geoid (as for example in [5]) is not applied here, as these fields do not correlate with the internal structure of the lithosphere. This is a result of mass compensation between the crust and the upper mantle (e.g. a thin, uplifted crust often correlates with a low-density upper mantle) which reduces the total gravitational effect [24]. Thus, the analysis of observed gravity or the geoid alone provides a poor resolution for the density structure of the lithosphere and upper mantle.

In the first step of this study we calculate the mantle gravity field and the residual topography. Both fields contain information on the mantle density structure, thereby providing a tool to compare different cratons, as well as contrasting cratonic with non-cratonic lithosphere.

In a second step we calculate the gravitational effect induced by upper-mantle temperature variations. Two independent constraints on the thermal state of the upper mantle are used here. For the continental lithosphere, which is the main object of this study, the temperature distribution was taken largely from [3], as deduced from surface heat flow and crustal heat production data. For oceanic areas and for those parts of the continents where the steady-state thermal conductivity problem is not valid, density variations in the lithosphere are estimated from S-wave velocities according to the S20 tomography model [19].
In a third step we remove the effect of temperature variations in the mantle lithosphere from the mantle gravity to uncover the effect of purely compositional variations. The amplitudes of the 'compositional' gravity anomalies for the individual cratons then provide constraints for an estimate of the density changes due to lithospheric depletion.

\section{Mantle gravity and residual topography}

The calculation of mantle gravity anomalies requires data on the thickness and density of crustal layers. Several global models of the crustal structure are presently available. The CRUST5.1 model represents $5^{\circ} \times 5^{\circ}$ averaged crustal data derived from seismic studies [17]. It was used earlier to calculate mantle and isostatic gravity anomalies and residual topography [24-26] as well as longwavelength dynamic surface topography $[15,27$, 28]. Here, the most recent $2^{\circ} \times 2^{\circ}$ global model of crustal structure, CRUST2.0, was used, which is supplemented by $1^{\circ} \times 1^{\circ}$ sedimentary thickness data [29]. This model was then significantly improved by including high-resolution seismic data for most of Eurasia and North America [30,31]. The gravitational effects of the differences between the new crustal model and CRUST5.1 sometimes exceed $100 \mathrm{mGal}$, even on a large scale for spherical harmonics up to degree 20 .

In order to eliminate signals of the crust from the surface gravity field, the gravitational effect of topography, bathymetry, sediments and consolidated crust down to the Moho was calculated with respect to a homogeneous reference density model. This was done by 3D forward computations (for a $1^{\circ} \times 1^{\circ}$ expanded grid) which account for both lateral and vertical density anomalies [25]. The reference density model corresponds to old (180 Ma) oceanic lithosphere according to the cooling plate model [32]. Only the mean value of the residual gravity field depends on the adoption of the reference model, which has no impact on the conclusions derived in this study.

Over oceanic areas, in addition, the gravity effect of thermally induced density variations with respect to the reference model (old ocean) was 
calculated based on age data for the ocean floor [34]. Temperature variations within oceanic lithospheric plates as a function of age were determined using the formula for the cooling plate model [32].

The residual (mantle) gravity field was then calculated by subtracting the crustal (and, over the ocean, lithospheric) gravity effect (including topography/bathymetry) from observed free-air gravity anomalies (model EGM96 [33]). By doing this, we also remove the effect of the perturbations of near-surface boundaries, which are due to the dynamic effect of mantle flow, i.e. non-isostatic topography. The same is true for the gravity effect of postglacial rebound topography. Thus, apart from uncertainties in the initial data, the residual gravity now reveals only the effect of mantle density inhomogeneities. This opens the possibility of modeling the mantle density structure nearly independently from its viscosity distribution. The average level of the residual gravity field was afterwards shifted to zero. We use gravity disturbances instead of gravity anomalies to account for the masses between the reference ellipsoid and geoid [35]. But, for convenience we shall henceforth use the term 'gravity anomalies'.

The resulting mantle gravity field is shown in Fig. 1. This map and the following maps are restricted to a degree/order 20 spectral resolution, corresponding to a spatial resolution of about $1000 \mathrm{~km}$ half-wavelength on the surface. Thus, our results refer to average properties of large lithospheric blocks. The reason to limit the study to the 20th spherical harmonic degree is to provide a homogeneous analysis of all cratons over the world. The mantle gravity anomalies vary approximately from $-250 \mathrm{mGal}$ to $+150 \mathrm{mGal}$. The largest positive gravity anomalies are associated with the Andes, the East European Platform, the Alpine-Mediterranean fold belt, and the central and southeastern parts of North America. The largest negative anomalies are associated with vast Cenozoic regions of rifting and crustal extension: the East-African Rift and the Basin and Range Province of the western USA. In addition, a strong negative anomaly is found in the southwestern Pacific. Negative anomalies found over Antarctica could be an artefact resulting from a poor knowledge of the crustal structure, and are not interpreted here.

Kaban and Schwintzer [24] discuss in detail the potential errors when computing large-scale anomalies of the mantle gravity field. The dominant source of errors are uncertainties of the density distribution within the crust. On continents, the total error varies from about $35 \mathrm{mGal}$ over areas where the crustal structure is well known (e.g. North America, most of Eurasia and Australia) to about $90 \mathrm{mGal}$ over areas with poor data coverage (e.g. South America and Africa). Over the oceans, the error varies from $8 \mathrm{mGal}$ for the well defined normal oceanic lithosphere to 40 mGal over anomalous oceanic regions, not taking into account possible errors in the 'cooling ocean lithosphere' model. These errors will be incorporated in the sensitivity analysis of the present results.

To characterize the isostatic state of the lithosphere, the residual topography $\left(t_{\text {res }}\right)$, which is equivalent to the total sum of anomalous masses within a $1^{\circ} \times 1^{\circ}$ lithospheric column (with respect to a reference column), is evaluated for each column applying the following formula:

$t_{\text {res }}=\frac{1}{\bar{\rho}}\left(\rho_{\text {top }}\right) t_{\text {obs }}+\frac{1}{\bar{\rho}} \int_{0}^{Z} \Delta \rho(h)\left(\frac{R-h}{R}\right)^{2} \mathrm{~d} h$

where: $\rho_{\text {top }}$ is the average block density (including the effects of ice and sediments) of topography $\left(t_{\text {obs }}\right) ; h$ is depth with respect to the geoid; $Z$ is the depth limit of integration and is equal to the depth of the Moho for continental areas and to the depth of the bottom of the lithosphere for oceanic areas $(130 \mathrm{~km}$ according to the cooling plate model); $R$ is the mean radius of the Earth; $\Delta \rho(h)$ is a density perturbation in the crust (including water) and in the upper mantle under oceans relative to the density stratification in the reference model; $\bar{\rho}$ is the average density of the residual topography and is set to $2670 \mathrm{~kg} / \mathrm{m}^{3}$ to convert the residual mass into the residual topographic height $t_{\text {res }}$. The reference column includes $6.4 \mathrm{~km}$ of water with a density of $1030 \mathrm{~kg} / \mathrm{m}^{3}$, a $7.2 \mathrm{~km}$ thick crust with a constant average density of $2850 \mathrm{~kg} / \mathrm{m}^{3}$ and an upper mantle with a density distribution corresponding to the cooling plate 


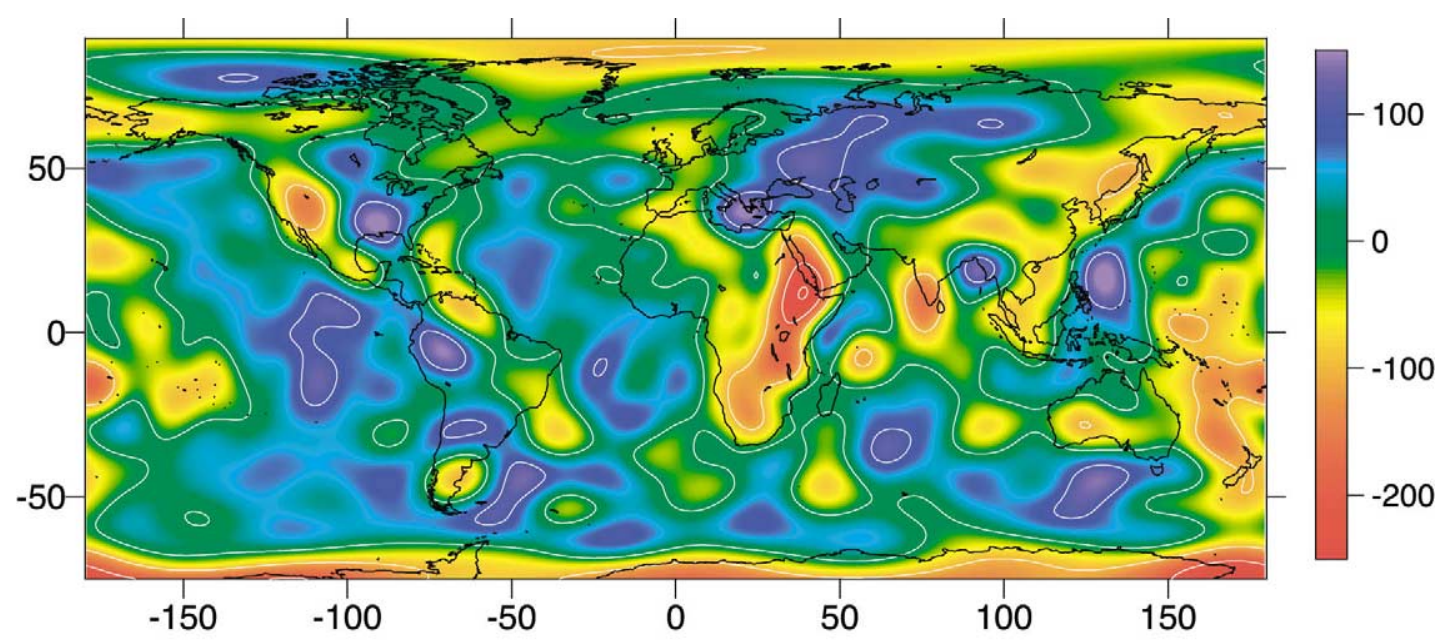

Fig. 1. Mantle gravity anomalies (in mGal), calculated by subtracting from observed gravity (a) globally, the crustal gravity effect including topography and bathymetry, and (b) for the oceans, the gravity effect of the cooling oceanic lithosphere (plate model) estimated from ocean floor age data. The anomalies are truncated after degree/order 20 and centered by subtracting the mean value.

model for the oceanic lithosphere with an age of $180 \mathrm{Ma}$.

The calculated residual topography, filtered to a spectral resolution up to degree/order 20 , is shown in Fig. 2. The residual topography varies between $-1.0 \mathrm{~km}$ and $+2.5 \mathrm{~km}$; the zero level corresponds to an old (180 Ma) ocean reference column. The uncertainties of the calculated variations of the residual topography stem from the same error sources as in mantle gravity. On the continents, we estimate the residual topography error to be about $0.35 \mathrm{~km}$ for the areas with a well known crustal structure (e.g. most of North America and Eurasia, Australia) and to be as large as $0.8 \mathrm{~km}$ for the regions with a poor seismic data coverage (e.g. South America and Africa).

For oceanic areas our residual topography map is close to the previously published one [25] and to the map of Panasyuk and Hager [26] based upon the cooling plate model. However, the differences on continents are substantial. This is especially true for North America and Eurasia where, contrary to our previous calculations, the crustal model is now based on high-resolution (mostly) seismic data, rather than the global model. It is also important to note that at this stage we do not apply any correction for the subcrustal continen- tal tectosphere, as was done by Panasyuk and Hager [26].

Continental residual topography arises from two sources. First, continental residual topography depends on the density distribution in the uppermost mantle: highs are supported by lowdensity lithosphere roots while lows are balanced by high-density anchors. In accordance with [25], we assume that the lithospheric part of the upper mantle is preserved for a relatively long time and does not participate in mantle convection. The second source of the residual topography is normal stress at the base of the lithosphere due to mantle flow. This part of the residual topography is defined as 'dynamic' topography. Despite the formal discrimination between the two sources, the effect of large-scale upper mantle density variations, whether from below or from inside the lithosphere, on residual topography is similar. This is confirmed by numerical calculations that use topography kernels (Green's functions) to model upper mantle density inhomogeneities. For spherical harmonics of degree 2-20 and density anomalies at depths above $300 \mathrm{~km}$, the topography kernels differ at most by $10 \%$ from those for a purely isostatic model (e.g. [36]). We consider this difference to be insignificant, especially 


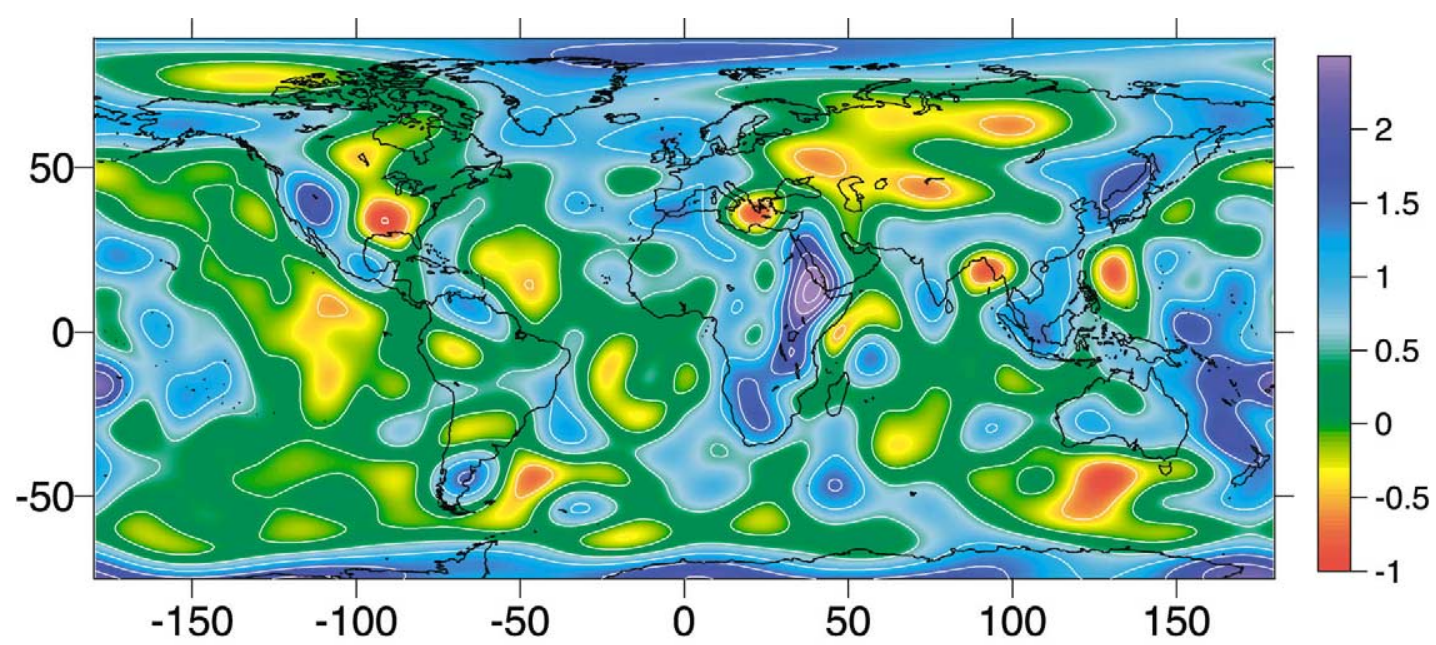

Fig. 2. Residual topography (in $\mathrm{km}$ ), calculated in spherical harmonics up to degree/order 20 by removing isostatic compensation masses produced by the crustal density structure and by the oceanic lithosphere (for the model of a cooling plate in accordance with the ocean floor age data) from observed topography. Zero level corresponds to $180 \mathrm{Ma}$ old standard oceanic lithosphere (cooling plate).

with regard to the determination error of the residual topography.

The influence of local isostatic disturbances on the residual topography due to elastic support of external and internal loads can be neglected in this long-wavelength analysis (e.g. [37]). Estimations based on the elastic plate equations (e.g. [38]) show that the difference between a purely isostatic and disturbed isostatic residual topography does not exceed $7 \%$ at harmonic degree 20 even if we assume a nearly maximal $70 \mathrm{~km}$ elastic plate thickness. This difference rapidly decreases with decreasing harmonic degree, thus overall this error source is much smaller than the crustal model ones. Postglacial topography depressions hardly exceed several tens of meters and also do not affect the results of this study.

It is difficult to estimate the dynamic input of deep inhomogeneities to residual topography over continents without considering a complete global dynamic model of the Earth. Different authors give amplitudes of the dynamic topography ranging from $\pm 0.5 \mathrm{~km}[39]$ to $\pm 1 \mathrm{~km}[40]$ and $\pm 2 \mathrm{~km}$ [27]. However, an indirect guess may be obtained by comparison with the mantle gravity field. As already mentioned, the effect of dynamic deformations of the Earth's surface is subtracted in the mantle gravity anomalies, since these deformations are part of the observed topography and crustal structure. Thus the dynamic contribution can be considered less important when mantle gravity anomalies and residual topography are in good correspondence, that is inversely correlated with an appropriate scaling factor. In Figs. 1 and 2, regions with large negative residual gravity anomalies are characterized by large positive residual topography and vice versa. Both amplitudes vary similarly when applying an appropriate scaling factor. This indicates that the dynamic contribution is small relative to the total variations of the residual topography. Nevertheless, further analysis is restricted mostly to mantle gravity, because it is less dependent on these factors.

\section{Bulk density structure of the continental roots}

It is difficult to correlate tectonic structures defined in detailed geological maps with low-resolution models, e.g. seismic anomaly maps derived from global tomography. Thus, for an analysis of the properties of the continental roots it is necessary to prepare a 'cratonic' map with a res- 


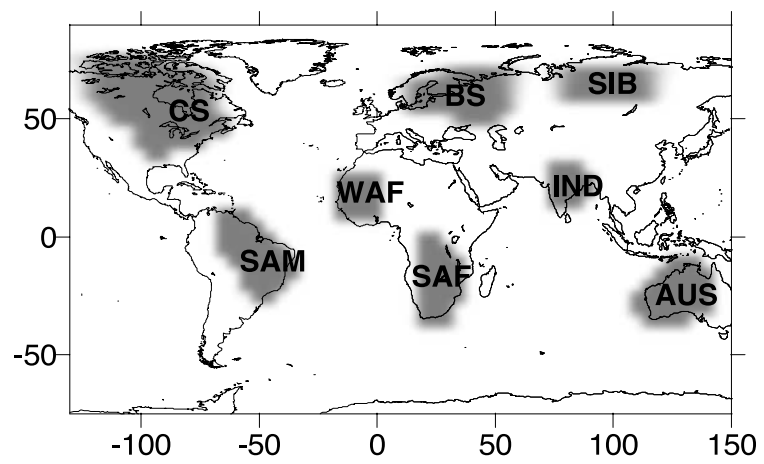

Fig. 3. Cratonic regions as identified from S-wave velocity anomalies in the upper $200 \mathrm{~km}$ of the global seismic tomography model S20 [19]. Legend: CS, Canadian shield; AUS, western Australia; BS, Baltic shield and East European Platform; SIB, Siberian Platform; SAF, South African craton; IND, Indian shield; SAM, South American craton; WAF, West African craton.

olution corresponding to the one addressed here. The objective of this study is an inter-cratonic comparison of lithospheric density structure. Since shear-wave velocities in the upper mantle are mostly controlled by temperature variations [41], seismic data may be used to define cratonic boundaries. Following Pari and Peltier [27,42], we focus our analysis only on those cratons which reveal high shear-wave velocities at a depth of $100-200 \mathrm{~km}$. We therefore define cratons as continental zones with relatively high velocities in the upper mantle according to model S20 [19]. Craton boundaries are defined as the location of the maximum horizontal gradient of the $V_{\mathrm{s}}$ anomaly pattern.

Continental roots, as resolved in the $\mathbf{S} 20$ model, are shown in Fig. 3 and include: the Canadian shield (CS), the Baltic shield and a part of the
East European Platform (BS), the Siberian Platform (SIB), the South African craton (SAF), the West African craton (WAF), the Indian shield (IND), the South American craton (SAM) and western Australian craton (AUS). We do not discuss the lithospheric structure of other known cratonic regions (the Sino-Korean, Congo and Tanzanian cratons, and Greenland) as these do not reveal distinct positive $V_{\mathrm{s}}$ anomalies in the S20 model. These cratons are either not resolved in global tomography because of their small size or poor ray coverage, or were reworked since the Precambrian and do not have deep lithospheric roots. The crustal data for Antarctica are very sparse and we do not consider this continent further here.

Histograms of the values of mantle gravity and residual topography, calculated for a $5^{\circ} \times 5^{\circ}$ grid over the cratonic regions of Fig. 3, are shown in Figs. 4 and 5, and the mean and rms (root mean square) values are given in Table 1 . To start the analysis, overall averaged cratonic lithosphere is compared with the 'normal' old oceanic lithosphere, taken here as reference. The 'normal' ocean is defined as a part of the whole ocean where topography fits the cooling oceanic lithosphere model and residual topography is insignificant (variations do not exceed $\pm 0.4 \mathrm{~km}$ and the average level is equal to zero). On average, the mantle gravity over the continental roots is only slightly less $(-8 \mathrm{mGal}$ versus $46 \mathrm{mGal})$ and the residual topography only slightly higher $(0.4 \mathrm{~km}$ versus $0 \mathrm{~km}$ ) compared with 'normal' ocean and the differences do not exceed the rms values (Figs. 4 and 5, Table 1).

We now look for differences in the lithospheric densities between cratons. An analysis of mantle

Table 1

Residual gravity and residual topography anomalies: mean and root mean square (rms) values for cratonic regions (Fig. 3) and, for reference, 'normal' ocean

\begin{tabular}{lllllllllrr}
\hline & $\begin{array}{l}\text { 'Normal' } \\
\text { Ocean }\end{array}$ & $\begin{array}{l}\text { Average } \\
\text { for all } \\
\text { cratons }\end{array}$ & $\begin{array}{l}\text { Baltic } \\
\text { shield }\end{array}$ & $\begin{array}{l}\text { Siberian } \\
\text { craton }\end{array}$ & $\begin{array}{l}\text { Canadian } \\
\text { shield }\end{array}$ & $\begin{array}{l}\text { Western } \\
\text { Australia }\end{array}$ & $\begin{array}{l}\text { West } \\
\text { African } \\
\text { craton }\end{array}$ & $\begin{array}{l}\text { Indian } \\
\text { shield }\end{array}$ & $\begin{array}{l}\text { South } \\
\text { American } \\
\text { craton }\end{array}$ & $\begin{array}{l}\text { South } \\
\text { African } \\
\text { craton }\end{array}$ \\
\hline$t_{\text {res }}[\mathrm{km}]$ & 0.0 & 0.36 & -0.13 & -0.43 & 0.03 & 0.53 & 0.43 & 0.47 & 0.51 & 1.15 \\
rms $[\mathrm{km}]$ & 0.28 & 0.5 & 0.35 & 0.15 & 0.32 & 0.24 & 0.10 & 0.38 & 0.27 & 0.37 \\
$g_{\text {res }[\mathrm{mGal}]}$ & 46 & -8 & 64 & 74 & 15 & -27 & 7 & -32 & -21 & -96 \\
rms $[\mathrm{mGal}]$ & 32 & 59 & 41 & 16 & 40 & 39 & 11 & 48 & 29 & 39 \\
\hline
\end{tabular}


gravity and residual topography shows that despite a partial overlap, the mean values for the individual cratons cover a large range: from -100 to $+70 \mathrm{mGal}$ and from -0.1 to $+1.5 \mathrm{~km}$, respectively (Figs. 4 and 5, Table 1). These values significantly exceed the uncertainties of their determination. This suggests that density anomalies in the subcrustal lithosphere, produced by both temperature and compositional variations, vary significantly among the cratons.

Sorted by the inferred density of the subcrustal lithosphere, the cratonic regions considered in this study (Fig. 3) fall into the same two groups (Table 1), as was noted previously by Artemieva and Mooney [3] from the analysis of the lithospheric thermal regime. The largest positive residual gravity anomalies ( $>70 \mathrm{mGal})$ and large negative residual topography $(<-0.5 \mathrm{~km})$ are observed for

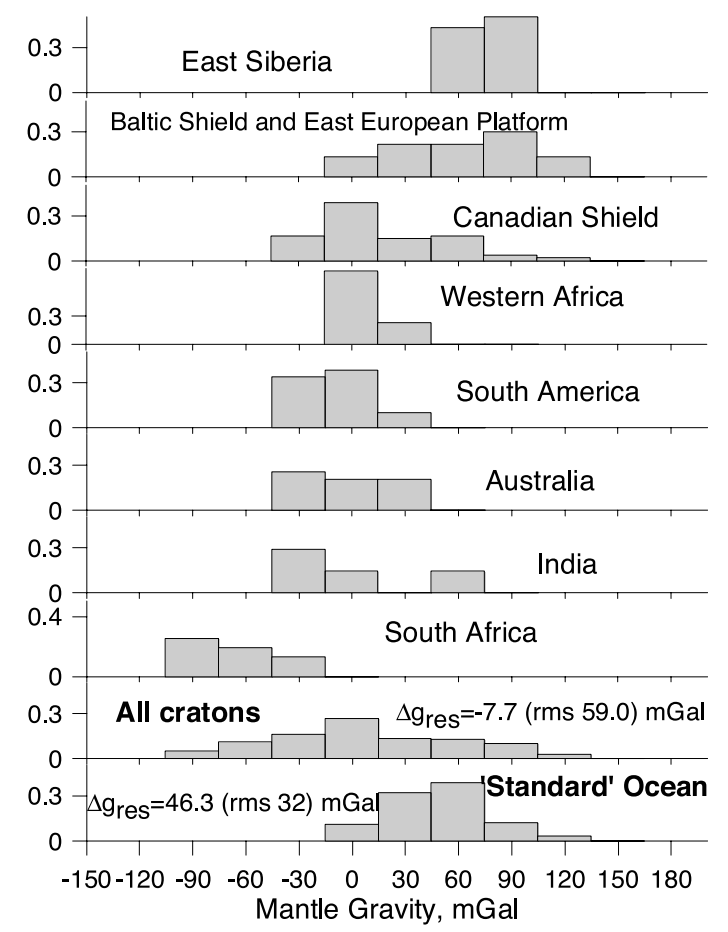

Fig. 4. The histograms of mantle gravity (Fig. 1) for the cratonic areas (Fig. 3) and over 'normal' ocean. 'Normal' ocean is defined as that part of the world' ocean where the ocean depth and the lithospheric thickness fit, in general, the cooling plate model. The vertical axes give the relative frequency of the values calculated for a $5^{\circ} \times 5^{\circ}$ grid in steps of 30 mGal.

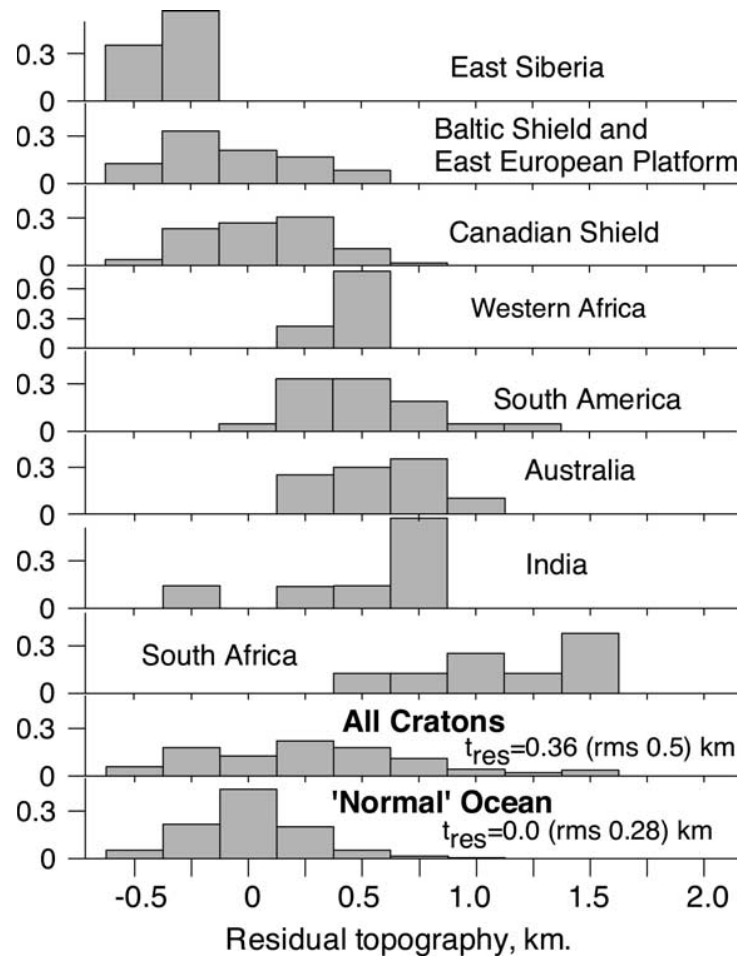

Fig. 5. The histograms of residual topography (Fig. 2) for the cratonic areas (Fig. 3) and for 'normal' ocean. The vertical axes give the relative frequency of the values calculated for a $5^{\circ} \times 5^{\circ}$ grid in steps of $0.25 \mathrm{~km}$.

the Baltic shield, the East European Platform, and the Siberian Platform. On average, positive mantle gravity anomalies with a small amplitude (0-20 mGal) are found for the Canadian shield and the West African craton. However, for the West African craton the average residual topography value is positive, while for the Canadian shield it is close to zero.

The second group of cratons includes mostly cratons of the southern hemisphere: Western Australia, the South American craton, the Indian shield and the South African craton. The South African craton reveals the largest negative gravity anomaly (-96 mGal) and the highest positive residual topography $(+1.15 \mathrm{~km})$. This topography may result from either an average subcrustal density that is less than found under other cratons, or can be caused by a dynamic effect of a lower mantle plume beneath central South Africa [43]. Other cratons of this second group have negative 
mantle gravity anomalies ( -20 to $-30 \mathrm{mGal})$ and positive residual topography (about $+0.5 \mathrm{~km}$ ).

The subdivision of the cratons into two groups by the density of their roots is in agreement with their thermal regime and inferred lithospheric thermal thickness [3]. The Baltic shield and the Siberian Platform have a lithospheric thermal thickness of $300 \mathrm{~km}$ and more, while the roots beneath the cratons of the southern hemisphere are only $200-220 \mathrm{~km}$ thick. Thus, the differences of the lithosphere density between the cratons may be at least partially explained by the differences in their thermal regime. We discuss this issue further in the next sections.

It is useful to compare these results, derived from gravity and crustal structure data, with global shear-wave $\left(V_{\mathrm{s}}\right)$ models for the upper mantle. The average $V_{\mathrm{s}}$ velocities from the $\mathrm{S} 20$ model [19] are plotted versus average mantle gravity (Fig. 6) and residual topography (Fig. 7). Despite a large scatter, a general tendency becomes evident: cratons with high $\mathrm{S}$-wave velocities (e.g. the Siberian Platform, the Baltic shield including parts of the

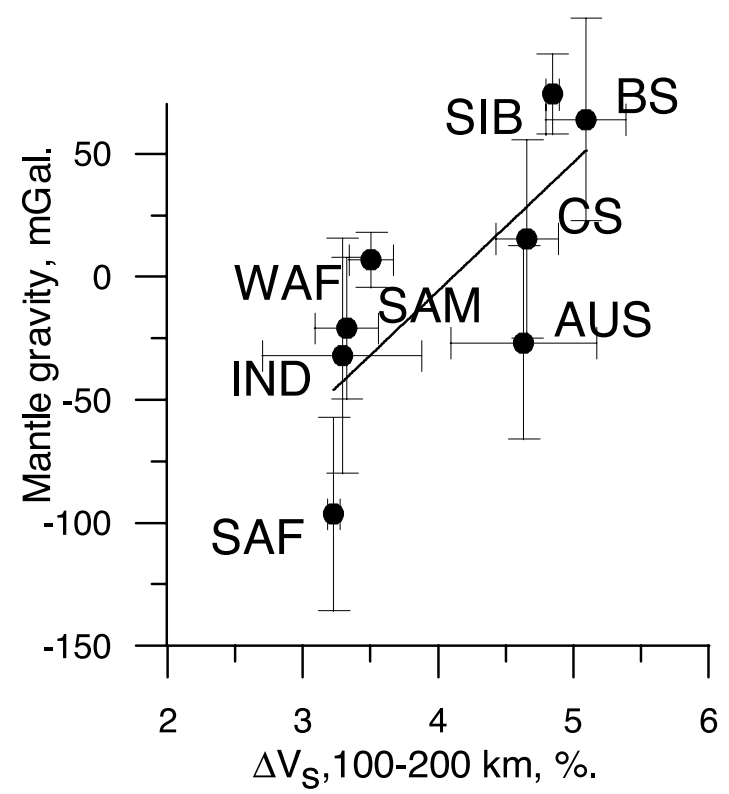

Fig. 6. S-wave velocity anomalies calculated from the S20 global tomography model [19] and averaged over the depth interval $100-200 \mathrm{~km}$ for the individual cratons in Fig. 3 versus residual gravity (mGal). The $V_{\mathrm{s}}$ perturbations are given in \% relative to PREM.

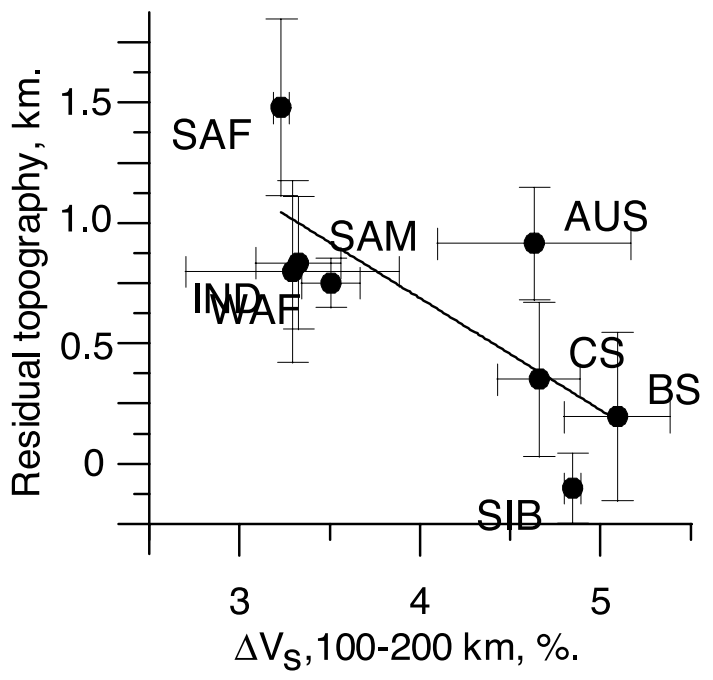

Fig. 7. S-wave velocity anomalies calculated from the S20 global tomography model [19] and averaged over the depth interval 100-200 $\mathrm{km}$ for the individual cratons shown in Fig. 3 versus residual topography $(\mathrm{km})$. The $V_{\mathrm{s}}$ perturbations are given in \% relative to PREM.

East European Platform, and the Canadian shield) have positive residual gravity anomalies and small (near-zero) residual topography anomalies and vice versa. The South African craton, where the $V_{\mathrm{s}}$ anomaly is nearly the same as beneath the Indian and South American cratons, has an unusually light upper mantle, as reflected by anomalously low values of residual gravity and a very high residual topography.

\section{Temperature variations in the upper mantle and their reflection in the gravity field}

We next account for the thermal state of the lithosphere to separate the effects of thermal expansion and composition on density anomalies. Our analysis is based on recent global calculations of the thermal regime of stable continental lithosphere [3], where lithospheric temperatures were estimated from the solution of the steady-state thermal conductivity equation. The global compilation of heat flow data [44], updated with more recent data, formed the basis of that modeling. The depth distribution of thermal parameters in the lithosphere was based on laboratory, seismic 


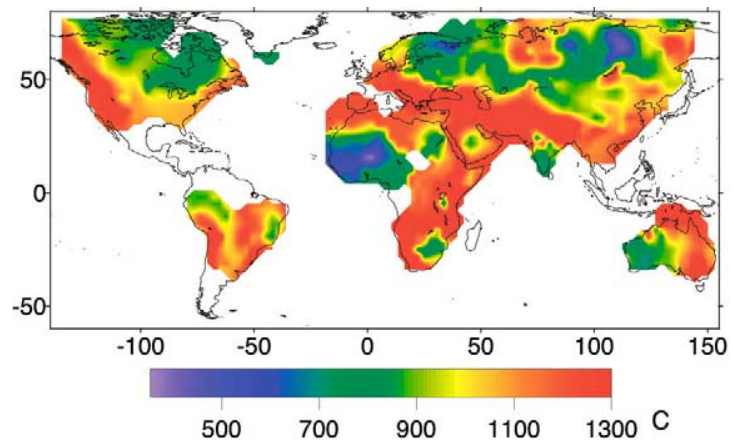

Fig. 8. Temperatures at $100 \mathrm{~km}$ depth (in ${ }^{\circ} \mathrm{C}$ ), determined from the heat flow data [3].

and petrologic data. The same thermal parameters are applied for all of the Precambrian cratons, which permits an accurate comparison of their thermal regimes. The calculated temperatures in stable continental regions were supplemented by published data based on alternative methods (e.g. petrologic constraints) for continental regions of active tectonics [3]. One of the resulting maps, the temperature distribution at $100 \mathrm{~km}$ depth, is shown in Fig. 8. At this depth, all cratons have relatively low lithospheric temperatures (typically in the range $500-800^{\circ} \mathrm{C}$ ), with the coldest temperatures beneath the Siberian Platform and West African craton $\left(500-600^{\circ} \mathrm{C}\right)$.

We then convert the lithospheric temperature variations into density variations via the thermal expansion coefficient $\left(\alpha=3.5 \times 10^{-5} \mathrm{~K}^{-1}\right)$. This parameter depends on the temperature and composition but possible variations are not large, typically $\pm 0.25 \times 10^{-5} \mathrm{~K}^{-1}[10,45]$. We use the same values of $\alpha$ globally in order to provide a stable result for a comparison of cratons and assuming that it should not vary significantly between the areas under similar conditions. Temperature-induced density variations based on the thermal model represented by Fig. 8 were supplemented by density constraints based on seismic velocities under the oceans and for those parts of the continents where heat flow data do not exist (white areas in Fig. 8). For this purpose we converted the S20 tomography model [19] into density assuming that the shear-wave velocity variations in the upper mantle result only from temperature variations. Note that in the S20 tomography mod- el the isotropic $V_{\mathrm{s}}$ variations are separated from the anisotropic variations that have clearly no relation to temperature variations.

The conversion of $\mathrm{S}$-wave velocities into densities is based on vertically averaged $V_{\text {s }}$ perturbations over five $50-\mathrm{km}$-thick layers from 25 to 275 $\mathrm{km}$, the maximum depth of the temperature estimations [3]. For the continental upper mantle we use the conversion coefficient of Karato [41], $d \ln \rho /$ $\mathrm{d} \ln V_{\mathrm{s}}=0.23$. A similar value is also found in related studies [45]. For oceanic regions we use the conversion coefficients estimated in a joint inversion of velocity and gravity data [24]. The densities estimated from the shear-wave velocities are assigned to the areas located at a distance of $5^{\circ}$ or more from the nearest data point in the thermal database [3]. They produce only a far-field gravity effect in cratonic areas, thus the uncertainties in the velocity-to-density conversion are not critical for this study. Next, the global distribution of temperature-induced density anomalies resulting from the two complementary data sets is interpolated using a standard kriging method. The gravity effect of the temperature-induced density anomalies averaged over $50-\mathrm{km}$-thick layers is calculated and accumulated over depth. Since we are going to compare this effect with the mantle gravity anomalies, we do not need to estimate the effect of surface deformations induced by mantle flow, and we restrict our calculations to the pure gravity signal resulting from deep density anomalies.

Fig. 9 shows the surface gravity effect of temperature variations over the depth range 25-275 $\mathrm{km}$. An uncertainty in this parameter comes from uncertainties in lithospheric temperatures and in the coefficient of thermal expansion. For the maximal temperature errors in the subcrustal lithosphere of $100^{\circ} \mathrm{C}$ [3], the uncertainty of the results shown in Fig. 9 is up to $50-70 \mathrm{mGal}$ for the cratons. Gravity anomalies induced by temperature variations in the uppermost mantle range from -200 to $+300 \mathrm{mGal}$, with significant variations over the entire Earth. As one would expect, negative anomalies mainly correlate with midocean ridges. The most significant positive anomalies are associated with the cratonic regions with thick lithospheric roots (Fig. 9). The ampli- 


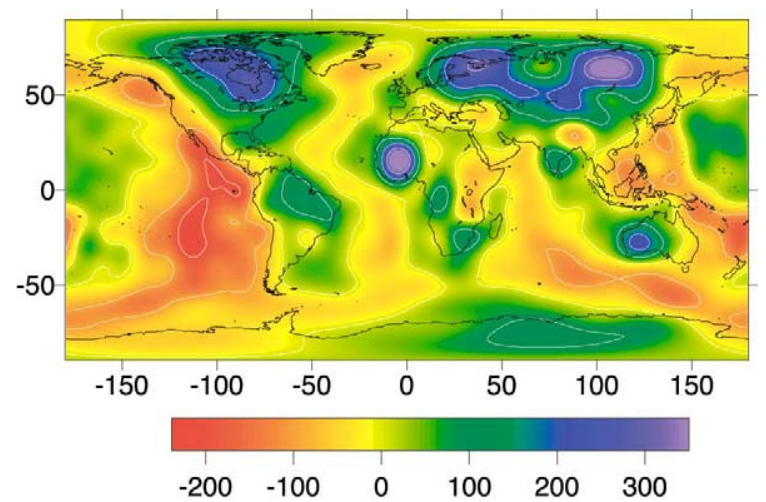

Fig. 9. Gravity effect (in $\mathrm{mGal}$ ) of temperature-induced density anomalies in the depth range $25-275 \mathrm{~km}$. The temperature distribution is based on the thermal calculations [3] for most parts of the continental areas (coverage according to Fig. 8) and a joint inversion of seismic and gravity data elsewhere [24].

tude of the lithospheric anomalies is there greater than $100 \mathrm{mGal}$, and in some regions (the Baltic shield, the Siberian Platform and the West African craton) these anomalies are as large as 250 $300 \mathrm{mGal}$ due to very low lithospheric temperatures.

The relationship between residual gravity anomalies (Fig. 1) and temperature-induced gravity variations is shown in Fig. 10 for the individual cratons. On the whole, there is a close linear correlation between the two parameters. Only the West African craton appears to differ significantly. For this region, data on the crustal structure are absent and the calculated residual gravity anomalies (Fig. 1) are based on a statistically averaged crustal model for areas of the same geological age [17]. A lack of information on the crustal structure and hence crustal contribution to the surface heat flow makes calculated mantle temperatures less reliable for West Africa than for other cratons [3]. Thus, this craton is excluded from further discussion.

Despite the close correlation, the range of mantle anomalies $(-100$ to $+75 \mathrm{mGal})$ averaged over the cratons is 1.4 times smaller than the range of temperature-induced gravity anomalies ( +50 to $+300 \mathrm{mGal}$; see Fig. 10). On average, about $60 \%$ of temperature-induced gravity variations are 'visible' in the residual (mantle) gravity field.
The value is slightly less for smaller values of the thermal expansion coefficient, but still remains significant.

These results show that on a global average the difference in the thermal regime of the lithosphere under cratons is compensated only by about $40 \%$ through compositional differences (i.e. by depletion). An almost complete compensation is reached for the coldest lithospheric roots (Baltic shield and Siberian Platform), whereas the relative increase in lithospheric temperature in other cratons is accompanied by a substantially lower change of density due to depletion. This conclusion contradicts the classical isopycnic hypothesis [11] that calls for a complete balance between temperature-induced and compositionally induced density anomalies in the cratonic lithosphere.

The non-equality of thermally and compositionally induced density variations may result from differences in the depth stratifications of the density variations. The compositionally induced density variations decrease more rapidly with depth than the thermal ones. As already mentioned, recent experimental studies of densities of the cratonic peridotites provide support for this idea. On average, shallow (spinel and low$T$ garnet) peridotites have bulk densities less than

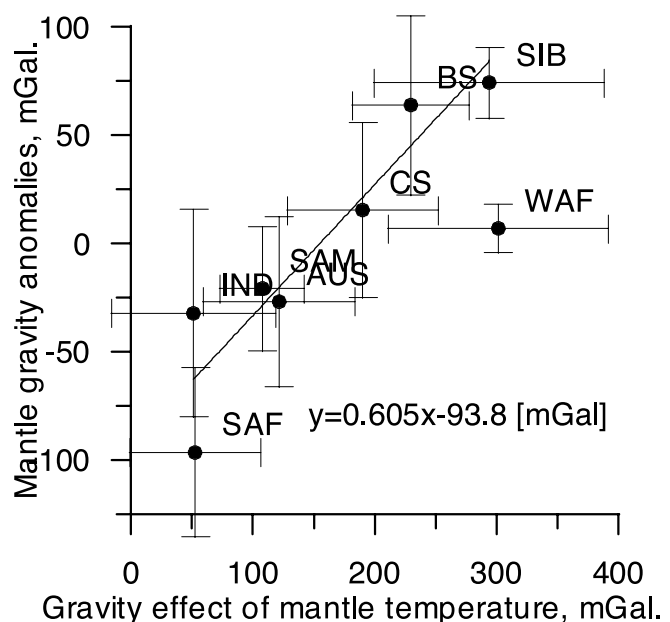

Fig. 10. Mantle gravity anomalies (y) averaged over the individual cratonic regions versus the gravity effect of temperature variations in the upper mantle $(x)$ as shown in Fig. 9. Error bars indicate $1 \sigma$-scattering about mean. 
required by the isopycnic relation, while most of the deep peridotites are denser [12]. This means that a simple removal of the lower, less depleted part of the roots by mantle convection or basal drag will make the cratonic lithosphere less dense and more buoyant.

\section{Gravity effect of compositional changes in the upper mantle}

In the above analysis we have calculated: (a) the residual gravity anomalies that reflect variations in both temperature and composition of the mantle, and (b) gravity anomalies induced by temperature variations in the upper mantle/lithosphere. By subtracting the latter from the former, one obtains the gravitational effect of compositional variations in the lithosphere.

The mantle gravity field also contains the signal from below $275 \mathrm{~km}$ depth that was the limit of the temperature calculations. However, this signal is much weaker than the upper mantle signal, and amounts to about $10 \%$ (15\% for degree- 3 terms) of the total mantle anomaly [24]. This conclusion agrees with results derived from joint inversion of global seismic tomography and gravity data $[15,46,47]$. For subtraction we use the gravitational effect of the deeper mantle horizons as determined by Kaban and Schwintzer [24]. Uncertainties in the deeper mantle modeling are of only minor importance for the interpretation of upper mantle gravity.

Fig. 11 shows the remaining gravity anomalies obtained by removing from the mantle anomalies the effects of temperature-induced density anomalies in the uppermost mantle and of the gravity signal from sources below $275 \mathrm{~km}$. It should be noted that in this case we do not use the cooling lithosphere model; rather the entire effect of the oceanic mantle is based on a conversion of the S20 model as determined in [24]. The remaining gravity anomalies should reflect the effect of compositional density variations in the upper mantle. The upper mantle 'compositional' gravity anomalies vary globally from $-300 \mathrm{mGal}$ to $+220 \mathrm{mGal}$. Over cratonic areas this signal is mainly due to the effect of the lithospheric roots. These areas are characterized by large gravity lows with an amplitude of around $-200 \mathrm{mGal}$. The largest negative anomaly (about $-400 \mathrm{mGal}$ ) is found for the West African craton; however, this result is not

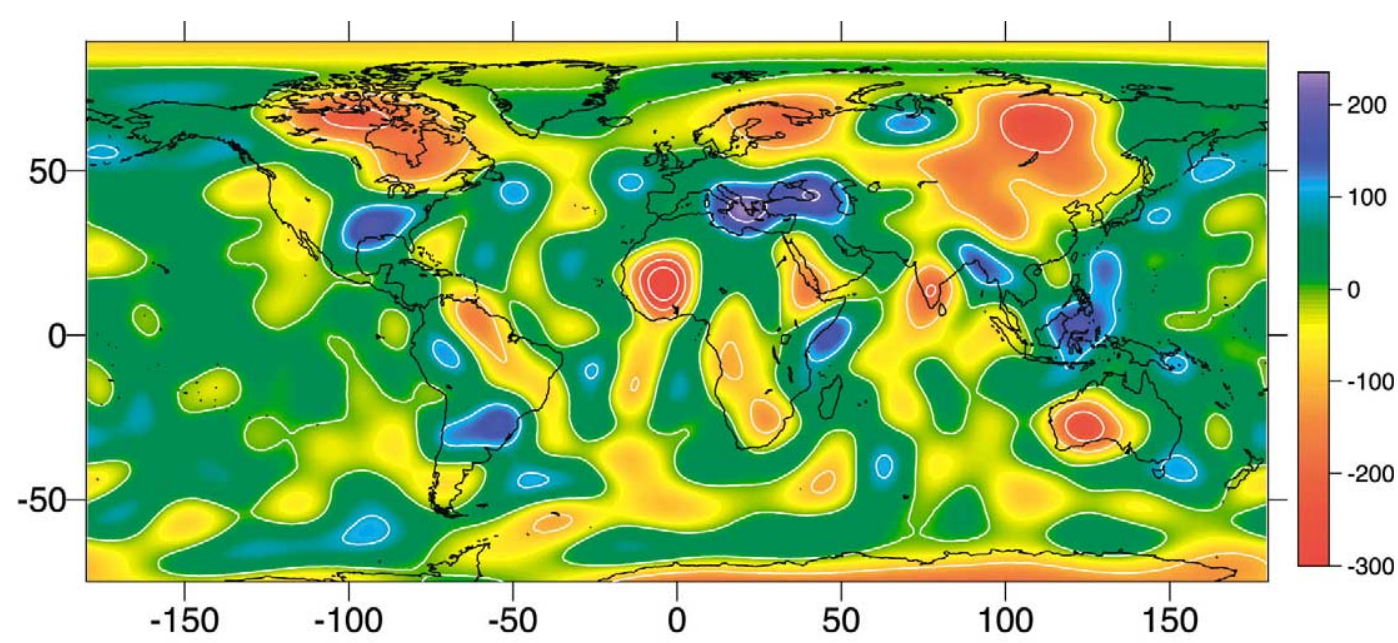

Fig. 11. Gravity anomalies (in $\mathrm{mGal}$ ) due to the compositional variations in the mantle obtained by subtracting from mantle gravity anomalies: (a) gravity effects of temperature-induced density variations in the lithosphere (Fig. 9) and (b) sublithospheric gravity signals. Here we do not use the cooling lithosphere model, but the entire effect of the oceanic mantle is based on a conversion of the S20 model as determined in [24]. The field is truncated after degree/order 20. The white isolines mark anomalies exceeding $100 \mathrm{mGal}$, assumed to be the maximum error in the crustal and temperature reductions of the gravity field. 
well constrained due to a lack of information on the crustal structure, as noted above.

Strong positive compositional gravity anomalies (Fig. 11), indicating a relatively dense composition within the lithosphere, are found in two distinct regions: (1) near ocean-continent and continent-continent subduction zones; and (2) within some continental interiors, for example in the southern part of North America adjoining the Gulf of Mexico. The origin of the latter positive anomaly is uncertain.

\section{Density anomalies in the cratonic lithosphere}

We use the compositional gravity anomalies (Fig. 11) to estimate the corresponding density changes under cratons. Since the solution of the inverse gravity problem is not unique, we apply two simple a priori constraints for the density distribution in the upper mantle, one related to the thickness of the chemical boundary layer (CBL) and one to the density change with depth. In the first model we assume that the thickness of CBL corresponds to the thermal boundary layer (TBL) and that the maximum depth of the compositional anomaly corresponds to the undulating bottom of the thermal lithosphere as determined in [3]. In the second model we assume that the CBL thickness is the same for all cratons, with the bottom at a depth of $200 \mathrm{~km}$ below Moho. These two models represent alternative ideas about the origin of the cratonic lithosphere. Outside the cratons we use a constant value $(90 \mathrm{~km}$ below Moho) for the CBL thickness. This value is arbitrary but does not significantly affect the results for cratonic areas. The sources of the compositional density anomalies under young continental and oceanic regions are located in a wide depth range and, for example, in the case of subducting slabs may extend down to the mantle transition zone. Thus, we do not consider the inversion results for non-cratonic areas, but take these to absorb the signal over non-cratonic areas.

A proper parametrization of the density-depth relationship is essential for gravity inversions. Recent petrological studies indicate that the degree of depletion decreases with depth $[12,13,23,48-$

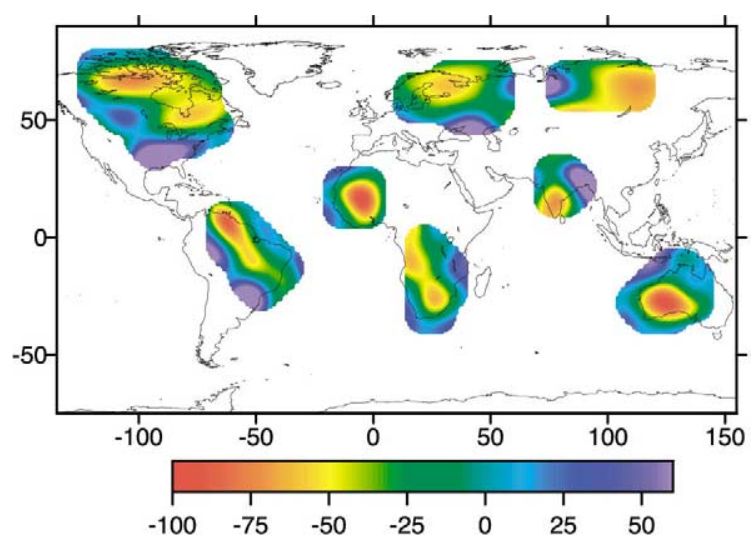

Fig. 12. Compositional density anomalies (in $\mathrm{kg} / \mathrm{m}^{3}$ ) in the subcrustal layer of the cratons as estimated from an inversion of the compositional gravity anomalies (Fig. 11). For inversion, the thickness of the CBL is assumed to be equal to the lithosphere thermal thickness [3].

50]; however, the exact depletion-depth profile is uncertain. For both models defined above we postulate that the compositional density anomaly decreases linearly from its maximum value just below the Moho to zero at the bottom of the CBL. Thus, the results we obtain should be scaled if one assumes a more complex change with depth. Rough estimates of the total mass balance show that the maximum density drop due to depletion (under the Moho) remains nearly the same if we assume a bimodal lithosphere, as found for the Slave craton [13], with a sharp transition at a depth of ca. $150 \mathrm{~km}$ from a very depleted upper layer to a much less depleted lower layer.

The results of the inversion are presented in Figs. 12 and 13. The uncertainties of the compositional density anomalies result from the CBL model assumptions and errors in the initial data. When propagating the uncertainties in the mantle gravity and temperature anomalies, the resulting cratonic density estimates can be in error by about $30 \%$ for the case assuming a constant CBL thickness. The uncertainty for the model with a variable lithospheric thickness is, however, less (about 20\%), because in this case the errors in lithospheric temperature and TBL thickness partially compensate each other. It is worth noting that our results characterize average properties of large lithospheric blocks (with half-wavelength of 
$1000 \mathrm{~km}$ ) and may not reflect small-scale lateral variations found in petrological data. Since the typical size of mantle convection cells is even larger than the averaging scale in the present study, the anomalies shown in Figs. 12 and 13 characterize large-scale fundamental properties of the upper mantle.

Density variations in the subcrustal layer under cratons for the first model (variable thickness of the CBL, being equal to the calculated TBL thickness) are shown in Fig. 12. In this case the compositional density deficiency of the cratonic lithosphere (with respect to normal mantle density) is similar for all the cratons, with the average density decrease due to depletion ranging from $1.1 \%$ to $1.5 \%$ at the top of the layer. A larger value $(1.7 \%)$ is found for West Africa, but the result for this craton is not well constrained by observations, as already mentioned. The average density decrease over all cratons considered is $1.3 \%$, corresponding to a density of $-49 \mathrm{~kg} / \mathrm{m}^{3}$ (Fig. 14). The spatial resolution applied in this study does not discern the fine geological structure over one continental root, thus the calculated average density variations reflect a mixture of Archean and Proterozoic lithosphere. The maximum depletion likely corresponds to the Archean parts of the cratons. For the individual cratons, the maximal density reduction varies from $1.7 \%$ to $2.5 \%$ (Fig. 14).

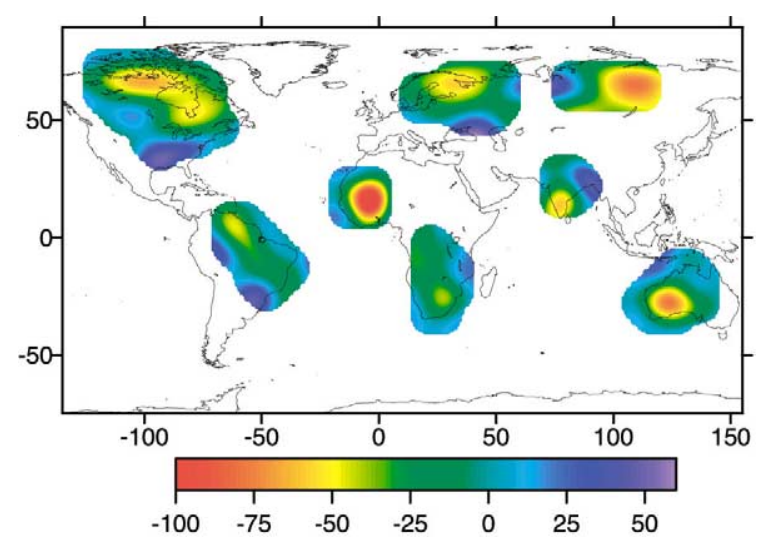

Fig. 13. Compositional density anomalies (in $\mathrm{kg} / \mathrm{m}^{3}$ ) in the subcrustal layer of the cratons as estimated from an inversion of the compositional gravity anomalies (Fig. 11). For inversion, the thickness of the CBL is assumed to be constant with its base $200 \mathrm{~km}$ below Moho.

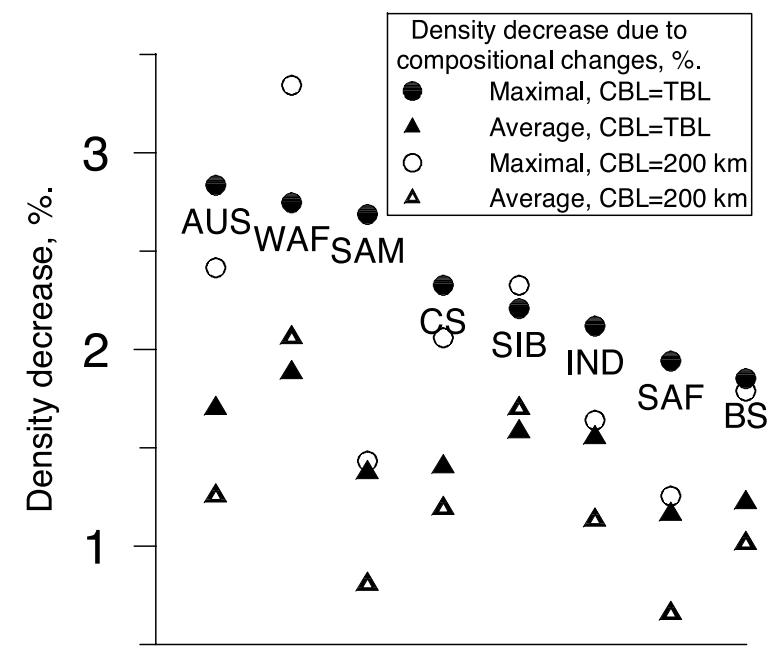

Fig. 14. Average and maximal values of the density decrease due to compositional changes for the individual cratons, as shown in Fig. 3. The cratons are sorted by decreasing density for the case when the thickness of the CBL is assumed to be equal to the thickness of the TBL.

These results generally agree with petrological studies that show that cratonic peridotites are up to $0.6-2.5 \%$ less dense compared to peridotites from the convecting mantle under the same $P-T$ conditions. A larger density decrease $(1.5-2.7 \%)$ is typical for low-temperature peridotites from the Archean roots, while a smaller decrease (0.6$1.4 \%)$ is typical for Proterozoic lithosphere and cratonic margins [6-9,51]. The largest density decrease is found for Western Australia and the Guyana craton of South America, in accord with recent petrological results [52]. Somewhat but not significantly smaller peak values of the density reduction are estimated for the Baltic shield and South Africa.

If we assume a constant thickness of the CBL (second model), the compositional density variations among the cratons get larger (Fig. 13). The density decrease averaged over the individual cratonic areas varies from $0.6 \%$ for South Africa to $1.5 \%$ for East Siberia. These values should be appropriately scaled if the thickness of the CBL differs from the assumed $200 \mathrm{~km}$. The same holds for the maximal values of the density reduction found for the individual cratons (1.2-2.4\%), once again disregarding Western Africa. 


\section{Conclusions}

We find that mantle gravity anomalies vary globally from $-250 \mathrm{mGal}$ to $+150 \mathrm{mGal}$, with the largest negative anomalies, indicating a lowdensity lithosphere, being associated with vast Cenozoic regions of plume-lithosphere interaction: the East African Rift, and the Basin and Range Province of the western USA. The largest positive anomalies over the continents are associated with the Andes, the East European Platform, the Alpine-Mediterranean fold belt and the centralsoutheastern part of North America. Residual topography varies globally from $-1.0 \mathrm{~km}$ to +2.5 $\mathrm{km}$ and is inversely correlated with the residual gravity anomalies.

For cratonic areas, we deduce from gravity and topography data a large range of density anomalies in the subcrustal lithosphere, produced by both temperature and compositional variations. The cratonic areas fall into two main groups. The largest positive residual gravity anomalies and the most significant negative residual topography are observed over Precambrian Eurasia (the Baltic shield, the East European Platform, the Ukrainian shield, and the Siberian craton). Cratons of the southern hemisphere (Western Australia, the South American craton, the Indian shield and Southern Africa) reveal negative mantle gravity anomalies and positive residual topography, with the most pronounced anomalies found for South Africa. The Canadian shield and West Africa have an intermediate position between these two groups. The cratons of the first group have a dense lithospheric mantle, while for the cratons of the second group the average lithospheric density is less than the upper mantle density beneath old ocean, which is here taken as the reference lithosphere.

We account for the thermal state of the lithosphere to separate the effects of composition and thermal expansion on density anomalies. Gravity anomalies induced by temperature variations in the cratonic lithosphere are typically greater than $+100 \mathrm{mGal}$ and in some regions (the Baltic shield, the Siberian craton, and the West African craton) reach $+250 \mathrm{mGal}$. We found that the temperature-induced gravity anomalies under cratons are well correlated with mantle gravity anomalies but the total amplitude of the latter is 1.5 times smaller than the range of pure temperature-induced gravity anomalies. This means that the density variations due to temperature are partly (about 40\%) compensated by density variations due to compositional differences. This conclusion contradicts the classical isopycnic hypothesis of Jordan [11] that predicts a complete balance between thermal and compositional buoyancy anomalies in the cratonic lithosphere. A plausible explanation is variation in the amount of compensation between thermal and compositional density changes with depth, and this concept is supported by recent petrological studies.

We calculate the gravity effect of compositional variations in the lithosphere by subtracting temperature-induced gravity anomalies from the mantle gravity anomalies. These compositional gravity anomalies vary from -300 to $+220 \mathrm{mGal}$. The cratonic areas are characterized by pronounced gravity lows, typically within the range -150 to $-250 \mathrm{mGal}$, implying corresponding compositional changes (i.e. depletion). Large positive compositional gravity anomalies are found in two distinct regions: (1) near ocean-continent and continent-continent subduction zones, and (2) within some continental interiors, e.g. in the southern part of North America.

We produce a map of compositional density anomalies in the cratonic lithosphere and compare the density reduction between different continental roots. The average density decrease for the individual cratons varies only slightly, between $1.1 \%$ and $1.5 \%$, assuming that the thickness of the CBL is proportional to the TBL thickness. These values depend to some extent on the proportion of Archean and Proterozoic lithosphere within each of the cratons. The maximal values of the compositional density reduction are within the interval $1.7-2.5 \%$, and should characterize the Archean portion of each area. This result is in general agreement with petrological studies.

If we assume that the thickness of the CBL is constant for all the cratons, the compositional density anomalies we obtain vary much more among the individual cratonic roots. For a 200km-thick CBL, the compositional density decrease 
averaged over each craton is between $0.6 \%$ and $1.5 \%$, with peaks from $1.2 \%$ to $2.4 \%$. These values agree somewhat less with petrological studies than in the case of a variable CBL thickness.

\section{Acknowledgements}

We are grateful to D. Abbott, M. Cara, J.-J. Lévèque, S. Sobolev and V.P. Trubitsyn for constructive discussions regarding this work. Thoughtful reviews by J.-C. Mareschal and W.L. Griffin improved the text greatly.[AC]

\section{References}

[1] H.N. Pollack, D.S. Chapman, On the regional variation of heat flow, geotherms and lithospheric thickness, Tectonophysics 38 (1977) 279-296.

[2] C. Jaupart, J.C. Mareschal, The thermal structure and thickness of continental roots, Lithos 48 (1999) 93-114.

[3] I.M. Artemieva, W.D. Mooney, Thermal thickness and evolution of Precambrian lithosphere: A global study, J. Geophys. Res. 106B (2001) 16387-16414.

[4] T.H. Jordan, Composition and development of the continental tectosphere, Nature 274 (1978) 544-548.

[5] S.S. Shapiro, B.H. Hager, T.H. Jordan, The continental tectosphere and Earth's long-wavelength gravity field, Lithos 48 (1999) 135-152.

[6] F.R. Boyd, R.H. McCallister, Densities of fertile and sterile garnet peridotites, Geophys. Res. Lett. 3 (1976) 509512.

[7] T.H. Jordan, Continents as a chemical boundary layer, Philos. Trans. R. Soc. London A 301 (1981) 359-373.

[8] F.R. Boyd, Compositional distinction between oceanic and cratonic lithosphere, Earth Planet. Sci. Lett. 96 (1989) 15-26.

[9] C.J. Hawkesworth, P.D. Kempton, N.W. Rogers, R.M. Ellam, P.W. van Calsteren, Continental mantle lithosphere, and shallow level enrichment process in the Earth's mantle, Earth Planet. Sci. Lett. 96 (1990) 256-268.

[10] Y.H. Poudjom Djomani, S.Y. O'Reilly, W.L. Griffin, P. Morgan, The density structure of subcontinental lithosphere through time, Earth Planet. Sci. Lett. 184 (2001) 605-621.

[11] T.H. Jordan, Structure and formation of the continental tectosphere, J. Petrol. 29 (1988) 11-37.

[12] F.R. Boyd, D.G. Pearson, S.A. Mertzman, Spinel-facies peridotites from the Kaapvaal root, in: J.J. Gurney, J.L. Gurney, M.D. Pascoe, S.H. Richardson (Eds.), Proc. VII Int. Kimberlite Conf., vol. 1, 1999, pp. 40-48.

[13] W.L. Griffin, B.J. Foyle, C.G. Ryan, N.J. Pearson, S.Y. O’Reilly, R. Davies, K. Kivi, E. van Achterbergh, L.M.
Natapov, Layered mantle lithosphere in the Lac de Gras Area, Slave Craton: Composition, structure and origin, J. Petrol. 40 (1999) 705-727.

[14] C.-T. Lee, R.L. Rudnick, Compositionally stratified cratonic lithosphere: petrology and geochemistry of peridotite xenoliths from the Labait Volcano, Tanzania, in: J.J. Gurney, J.L. Gurney, M.D. Pascoe, S.H. Richardson (Eds.), Proc. VII Int. Kimberlite Conf., vol. 2, 1999, pp. 503-521.

[15] A.M. Forte, H.K.C. Perry, Geodynamic evidence for a chemically depleted continental tectonosphere, Science 290 (2000) 1940-1944.

[16] W.L. Griffin, C.G. Ryan, F.V. Kaminsky, S.Y. O'Reilly, L.M. Natapov, T.T. Win, P.D. Kinny, I.P. Ilupin, The Siberian lithosphere traverse; mantle terranes and the assembly of the Siberian Craton, Tectonophysics 310 (1999) $1-35$.

[17] W.D. Mooney, G. Laske, T.G. Masters, CRUST 5.1: A global crustal model at $5^{\circ} \times 5^{\circ}$, J. Geophys. Res. 103B (1998) 727-747.

[18] S.P. Grand, Mantle shear structure beneath the Americas and surrounding oceans, J. Geophys. Res. 99B (1994) 11591-11621.

[19] G. Ekström, A.M. Dziewonski, The unique anisotropy of the Pacific upper mantle, Nature 394 (1998) 168-172.

[20] A.H.E. Röhm, R. Snieder, S. Goes, J. Trampert, Thermal structure of continental upper mantle inferred from S-wave velocity and surface heat flow, Earth Planet. Sci. Lett. 181 (2000) 395-407.

[21] W.L. Griffin, S. O'Reilly, C.G. Ryan, O. Gaul, D.A. Ionov, Secular variation in the composition of subcontinental lithospheric mantle: Geophysical and geodynamic implications, in: AGU Geodynam. Ser. 26, 'Structure and Evolution of Australian Continent', 1998, pp. 1-26.

[22] F.R. Boyd, D.G. Pearson, N.P. Pokhilenko, S.A. Mertzman, Cratonic mantle composition; evidence from Siberian xenoliths, EOS Trans. AGU 74 (1993) 321.

[23] C.-T. Lee, R.L. Rudnick, The formation and destruction of cratonic lithosphere: Insights from the Tanzanian craton, EOS Trans. AGU 78 (1997) 746.

[24] M.K. Kaban, P. Schwintzer, Oceanic upper mantle structure from experimental scaling of $\mathrm{V}_{\mathrm{s}}$ and density at different depths, Geophys. J. Int. 147 (2001) 199-214.

[25] M.K. Kaban, P. Schwintzer, P.S.A. Tikhotsky, Global isostatic gravity model of the Earth, Geophys. J. Int. 136 (1999) 519-536.

[26] S.V. Panasyuk, B.H. Hager, Models of isostatic and dynamic topography, geoid anomalies, and their uncertainties, J. Geophys. Res. 105B (2000) 28199-28209.

[27] G. Pari, W.R. Peltier, Subcontinental mantle dynamics: A further analysis based on the joint constraints of dynamic surface topography and free-air gravity, J. Geophys. Res. 105 (2000) 5635-5662.

[28] G. Pari, Crust 5.1-based inference of the Earth's dynamics surface topography: Geodynamic implications, Geophys. J. Int. 144 (2001) 501-516.

[29] C. Bassin, G. Laske, G. Masters, The current limits of 
resolution for surface wave tomography in North America, EOS Trans. AGU 81 (Suppl.) (2000) F897.

[30] M.K. Kaban, A gravity model of the North Eurasia crust and upper mantle: 1 . Mantle and isostatic residual gravity anomalies, Russ. J. Earth Sci. 3 (2001) 143-163.

[31] M.K. Kaban, W. Mooney, Density structure of the lithosphere in the southwestern United States and its tectonic significance, J. Geophys. Res. 106B (2001) 721-740.

[32] B.H. Hager, Global isostatic geoid anomalies for plate and boundary layer models of the lithosphere, Earth Planet. Sci. Lett. 63 (1983) 97-109.

[33] F.G. Lemoine, N.K. Pavlis, S.C. Kenyon, R.H. Rapp, E.C. Pavlis, B.F. Chao, New high-resolution model developed for Earth's gravitational field, EOS Trans. AGU 79 (1998) 113-118.

[34] R.D. Müller, W.R. Roest, J.-Y. Royer, L.M. Gahagan, J.G. Sclater, A digital age map of the ocean floor, Scripps Inst. of Oceanography, SIO Reference Series No. 93-30, Univ. of California, San Diego, CA, 1993.

[35] M.E. Chapman, J.H. Bodine, Considerations of the indirect effect in the marine gravity modelling, J. Geophys. Res. 84B (1979) 3889-3892.

[36] Y. Ricard, L. Fleitout, C. Froidevaux, Geoid heights and lithospheric stresses for a dynamic Earth, Ann. Geophys. 2 (1984) 267-286.

[37] A.R. Lowry, N.M. Ribe, R.B. Smith, Dynamic elevation of the Cordillera, western United States, J. Geophys. Res. 105 (2000) 23371-23390.

[38] B. Sheffels, M. McNutt, Role of subsurface loads and regional compensation in the isostatic balance of the Transverse Ranges, CA: evidence for intracontinental subduction, J. Geophys. Res. 91 (1986) 6419-6431.

[39] B.H. Hager, M.A. Richards, Long-wavelength variations in Earth's geoid; physical models and dynamical implications, Philos. Trans. R. Soc. London A 328 (1989) 309327.

[40] B. Steinberger, H. Schmeling, G. Marquart, Large-scale lithospheric stress field and topography induced by global mantle circulation, Earth Planet. Sci. Lett. 186 (2001) 7591.

[41] S.I. Karato, Importance of anelasticity in the interpretation of seismic tomography, Geophys. Res. Lett. 20 (1993) 1623-1626.

[42] G. Pari, W.R. Peltier, The free-air gravity constraint on subcontinental mantle dynamics, J. Geophys. Res. 101 (1996) 28115-28132.

[43] C. Lithgow-Bertelloni, P.G. Silver, Dynamic topography, plate driving forces and the African superswell, Nature 395 (1998) 269-272.

[44] H.N. Pollack, S.J. Hurter, J.R. Johnson, Heat flow from the Earth's interior: analysis of the global data set, Rev. Geophys. 31 (1993) 267-280.

[45] S. Sobolev, H. Zeyen, G. Stoll, F. Werling, R. Altherr, K. Fuchs, Upper mantle temperatures from teleseismic tomography of French Massif Central including effects of composition, mineral reactions, anharmonicity, anelasticity and partial melt, Earth Planet. Sci. Lett. 139 (1996) $147-163$

[46] Y. Ricard, M. Richard, C. Lithgow-Bertelloni, Y. Le Stunff, A geodynamic model of mantle density heterogeneity, J. Geophys. Res. 98B (1993) 21895-21909.

[47] V. Corrieu, C. Thoraval, Y. Ricard, Mantle dynamics and geoid Green functions, Geophys. J. Int. 120 (1995) 516 523 .

[48] M.G. Kopylova, J.K. Russell, H. Cookenboo, Petrology of peridotite and pyroxenite xenoliths from the Jericho kimberlite: implications for the thermal state of the mantle beneath the Slave Craton, Northern Canada, J. Petrol. 40 (1999) 79-104.

[49] N.J. Pearson, W.L. Griffin, B.J. Doyle, S.Y. O'Reilly, E. van Achterbergh, K. Kivi, Xenoliths from kimberlite pipes of the Lac de Gras Area, Slave craton, Canada, in: J.J. Gurney, J.L. Gurney, M.D. Pascoe, S.H. Richardson (Eds.), Proc. VII Int. Kimberlite Conf., vol. 2, 1999, pp. 644-658.

[50] O.F. Gaul, W.L. Griffi, S.Y. O'Reilly, N.J. Pearson, Mapping olivine composition in the lithospheric mantle, Earth Planet. Sci. Lett. 182 (2000) 223-235.

[51] D.G. Pearson, R.W. Carlson, S.B. Shirey, F.R. Boyd, P.H. Nixon, Stabilisation of Archaean lithospheric mantle; a Re-Os isotope study of peridotite xenoliths from the Kaapvaal Craton, Earth Planet. Sci. Lett. 134 (1995) 341357.

[52] F.V. Kaminsky, O.D. Zakharchenko, R. Davies, W.L. Griffin, G.K. Kharchatryan-Blinova, A.A. Shiryaev, Superdeep diamonds from the Juina area, Mato Grosso State, Brazil, Contrib. Mineral. Petrol. 140 (2001) 734 753 . 